\title{
Pregnancy outcomes are not altered by variation in thyroid function within the normal range in women free of thyroid disease
}

\author{
Flora Veltri' ${ }^{1}$ Pierre Kleynen ${ }^{1}$, Lidia Grabczan ${ }^{1}$, Alexandra Salajan², Serge Rozenberg ${ }^{2}$, Thierry Pepersack ${ }^{3}$ and \\ Kris Poppe ${ }^{1}$ \\ ${ }^{1}$ Endocrine Unit, Centre Hospitalier Universitaire Saint Pierre, Université Libre de Bruxelles (ULB), Brussels, Belgium, \\ ${ }^{2}$ Departement of Gynecology and Obstetrics, Centre Hospitalier Universitaire Saint Pierre, Université Libre de \\ Bruxelles (ULB), Brussels, Belgium, and ${ }^{3}$ Geriatric Unit, Centre Hospitalier Universitaire Saint Pierre, Université Libre \\ de Bruxelles (ULB), Brussels, Belgium \\ Correspondence \\ should be addressed \\ to K Poppe \\ Email \\ kris_poppe@stpierre-bru.be
}

\begin{abstract}
Objective: In the recently revised guidelines on the management of thyroid dysfunction during pregnancy, treatment with thyroid hormone (LT4) is not recommended in women without thyroid autoimmunity (TAI) and TSH levels in the range $2.5-4.0 \mathrm{mIU} / \mathrm{L}$, and in a recent study in that particular group of pregnant women, more complications were observed when a treatment with LT4 was given. The objective of the study was therefore to investigate whether variation in thyroid function within the normal (non-pregnant) range in women free of thyroid disease was associated with altered pregnancy outcomes?

Design: Cross-sectional data analysis of 1321 pregnant women nested within an ongoing prospective collection of pregnant women's data in a single centre in Brussels, Belgium.

Methods: Thyroid peroxidase antibodies (TPO-abs), thyroid-stimulating hormone (TSH), free T4 (FT4) and ferritin levels were measured and baseline characteristics were recorded. Women taking LT4, with TAI and thyroid function outside the normal non-pregnant range were excluded. Pregnancy outcomes and baseline characteristics were correlated with all TSH and FT4 levels within the normal range and compared between two groups (TSH cut-off $<$ and $\geq 2.5 \mathrm{mIU} / \mathrm{L}$ ). Results: Tobacco use was associated with higher serum TSH levels (OR: 1.38; Cl 95\%: 1.08-1.74); $P=0.009$. FT4 levels were inversely correlated with age and $\mathrm{BMI}$ ( $\mathrm{rho}=-0.096$ and $-0.089 ; P<0.001$ and 0.001 respectively) and positively correlated with ferritin levels (rho $=0.097 ; P<0.001)$. Postpartum haemorrhage $(>500 \mathrm{~mL}$ ) was inversely associated with serum FT4 levels (OR: 0.35; Cl 95\%: 0.13-0.96); $P=0.040$. Also $10 \%$ of women free of thyroid disease had serum TSH levels $\geq 2.5 \mathrm{mIU} / \mathrm{L}$.

Conclusions: Variation in thyroid function during the first trimester within the normal (non-pregnant) range in women free of thyroid disease was not associated with altered pregnancy outcomes. These results add evidence to the recommendation against LT4 treatment in pregnant women with high normal TSH levels and without TPO antibodies.
\end{abstract}

European Journal of

\section{Introduction}

The impact of subclinical thyroid dysfunction (SCH) and/or thyroid autoimmunity (TAI) on pregnancy outcomes such as miscarriage, preterm delivery, low birth weight, pre-eclampsia and gestational diabetes remains controversial $(1,2,3)$. One of the reasons for that may be the heterogeneity in the definition of SCH and how TAI is 
detected. In older studies, as cut-off, the upper limit of the assay of non-pregnant women was used $(4.0-5.0 \mathrm{mIU} / \mathrm{L})$ and since 2012, the Endocrine Society proposed a fixed cutoff of $2.5 \mathrm{mIU} / \mathrm{L}$, when no institutional one was available (4). In the recent guidelines of the American Thyroid Association (ATA), it is proposed to decrease the upper limit of the assay for non-pregnant women by $0.5 \mathrm{mIU} / \mathrm{L}$ when no institutional cut-off is available (in daily practice often $\sim 4.0 \mathrm{mIU} / \mathrm{L}$ ), and treatment with thyroid hormone (LT4) is not recommended in women without thyroid autoimmunity and TSH levels in the range $2.5-4.0 \mathrm{mIU} / \mathrm{L}$ (5). In a recent study, it has been shown that treatment with LT4 in pregnant women with serum TSH levels in the range $2.5-5.0 \mathrm{mIU} / \mathrm{L}$ led to a higher prevalence of preeclampsia and preterm deliveries $(5,6)$. In another study in pregnant women with $\mathrm{SCH}$ and TAI, it was shown that in the group with TSH levels between 2.5 and $5.0 \mathrm{mIU} / \mathrm{L}$, LT4 did not decrease the rate of preterm deliveries while it was the case when TSH was $>5.0 \mathrm{mIU} / \mathrm{L}$ (7). In a study by Negro and coworkers, LT4 did not decrease the miscarriage rate in pregnant women with TAI and TSH levels $<2.5 \mathrm{mIU} / \mathrm{L}$ as compared with placebo (8). In contrast, in another study, a lower miscarriage rate was observed in pregnant women with TAI treated with LT4 and aiming to obtain TSH levels $<2.5 \mathrm{mIU} / \mathrm{L}$ as compared with the group in which the TSH target was $\geq 2.5 \mathrm{mIU} / \mathrm{L}$ (9). In the study by Benhadi and coworkers, in pregnant women without overt thyroid dysfunction, the risk of child loss decreased with lower levels of maternal TSH (10). Finally, Negro and coworkers reported a lower first trimester miscarriage rate in pregnant women without TAI and TSH levels $<2.5 \mathrm{mIU} / \mathrm{L}$ compared with that in women with TSH levels between 2.5 and $5.0 \mathrm{mIU} / \mathrm{L}$ (11).

In order to avoid conflicting results between studies, due to the use of different TSH cut-offs; an interesting approach is to investigate associations between an outcome and TSH in a linear relationship (12). In a recent study in China, preconception high normal TSH levels within the non-pregnant normal range $(2.5-4.3 \mathrm{mIU} / \mathrm{L})$ were associated with an increased risk of adverse pregnancy outcomes, but TSH was measured 6 months before conception and no information on the presence of TAI was available (13). The presence of TAI is known to be an independent risk factor associated with pregnancy complications $(1,14)$.

Therefore and in order to investigate only the impact of serum TSH levels within the normal range, we excluded women with TSH levels outside the normal range, with TAI and treated with LT4.
The aims of the study were to investigate: (i) whether variation in serum TSH/FT4 levels within the normal (nonpregnant) range in women free of thyroid disease were associated with altered pregnancy outcomes, (ii) whether baseline characteristics and pregnancy outcome data were different between women with serum TSH levels $<$ and $\geq 2.5 \mathrm{mIU} / \mathrm{L}$ and (iii) what the distribution of serum TSH levels were in women free of thyroid disease.

\section{Subjects and methods}

\section{Overall study design}

The obstetrical clinic of the CHU St-Pierre is a downtown public university (tertiary referral) maternity in Brussels, Belgium. In our centre, the first antenatal consultation is systematically completed with a biological analysis including TSH, free T4 (FT4), thyroid peroxidase antibodies (TPO-abs) and ferritin measurement and obstetrical data (history and follow-up) are noted in a specific database (Cognos).

We report here on data of a cross-sectional analysis of pregnant women (period 2013-2014) that was nested within the ongoing prospective collection of women's obstetrical parameters and biological data. Finally and after exclusion of twin and assisted pregnancies $(n=98)$, women with TAI $(n=122)$, increased and decreased serum TSH levels $(n=144)$ and started on LT4 $(n=92)$, 1321 women were included for comparison/correlation of thyroid parameters with baseline characteristics and pregnancy outcome data. For the limits of serum TSH levels, the non-pregnant values were used. The upper limit of our assay is $4.0 \mathrm{mIU} / \mathrm{L}$ for non-pregnant women, a cut-off that is in line with the proposal of the recent ATA guidelines, in which it is mentioned 'to decrease the upper limit of the assay for non-pregnant women by $0.5 \mathrm{mIU} / \mathrm{L}$ when no institutional cut-off is available and that for the typical patient in early pregnancy, this corresponds to a TSH upper reference limit of $4.0 \mathrm{mU} / \mathrm{L}^{\prime}$ (5). For the lower limit, we used $0.3 \mathrm{mIU} / \mathrm{L}$, since we also wanted to exclude women with suppressed TSH levels.

In Fig. 1, we illustrate more in detail the inclusion/ exclusion criteria with a flowchart.

For the pregnancy outcomes, only data were recorded from women who had successful ongoing pregnancies. Furthermore, miscarriage was not taken into account in our study, since it is a heterogeneous outcome, easily underestimated (including biochemical and clinical miscarriage), associated with many other variables besides 


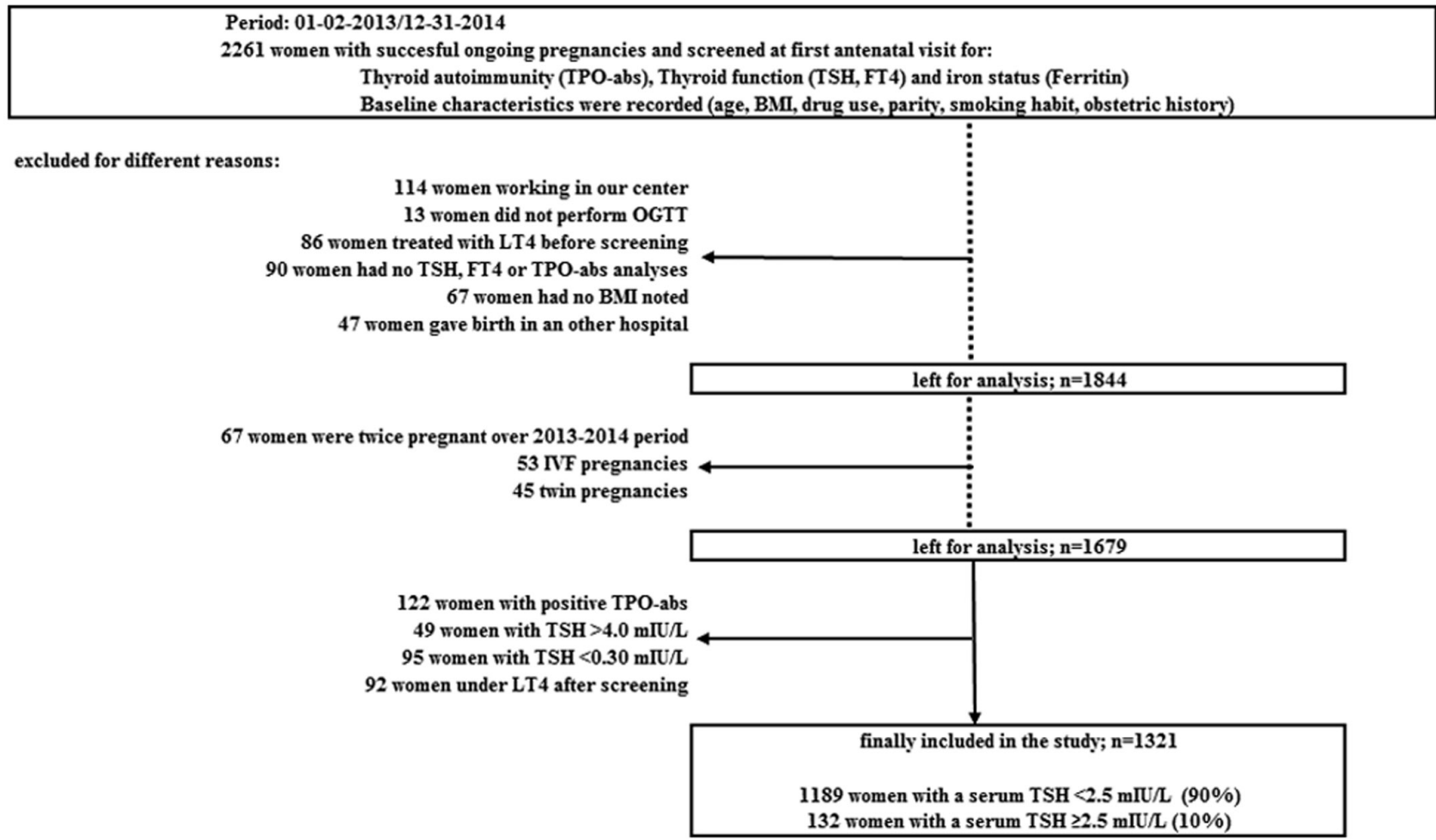

\section{Figure 1}

Flowchart illustrating the selection of the finally included women in the study.

TSH (15) and finally, it is strongly associated with the presence of TAI than with thyroid dysfunction $(1,14)$.

Gestational age determination was based on ultrasound findings. Intrauterine growth restriction (IUGR) was defined as a baby <10th percentile weight for gestational age and gender (16). Gestational diabetes (GDM) was present when fasting glycaemia was $\geq 92 \mathrm{mg} / \mathrm{dL}$ or when during the second trimester, women had a positive $75 \mathrm{~g}$ oral glucose tolerance test (OGTT); i.e. $1 \mathrm{~h}$ post prandial glycaemia ( $\geq 180 \mathrm{mg} / \mathrm{dL}$ ) or at $2 \mathrm{~h} \geq 153 \mathrm{mg} /$ dL (17). Pre-eclampsia was defined as a systolic blood pressure $\geq 140 \mathrm{mmHg}$ and/or a diastolic blood pressure $\geq 90 \mathrm{mmHg}$ and with a proteinuria $>0.3 \mathrm{~g} / 24 \mathrm{~h}$ after 20 weeks of amenorrhea (18).

In the two study groups ( $\mathrm{TSH}<$ and $\geq 2.5 \mathrm{mIU} / \mathrm{L}$ ), parameters were expressed as continuous values for TSH, FT4, ferritin, BMI, age, parity, gestational age, first prenatal visit, pregnancy length, birth weight and postpartum haemorrhage. As categorical data were expressed: iron deficiency (ferritin: $<15 \mu \mathrm{g} / \mathrm{L}$ ), obesity (BMI: $\geq 30 \mathrm{~kg} / \mathrm{m}^{2}$ ), older age ( $\geq 35$ years), tobacco use (yes/no), high parity ( $\geq 3$ children), history of $\geq 2$ miscarriages, GDM, preeclampsia,
IUGR, preterm birth ( $<37$ weeks), low birth weight $(<2.5 \mathrm{~kg})$ and important postpartum haemorrhage $(\geq 500 \mathrm{~mL})$.

The study was approved by the institutional review board (AK/15-11-114/4568).

\section{Serum assay}

All provisions were implemented by the laboratory of hormonology of our institution. Serum TSH, FT4 and TPOabs levels were measured using the Chemiluminescence Centaur XP Siemens Immunoanalyzer. The (non-pregnant) reference values were $0.3-4.0 \mathrm{mIU} / \mathrm{L}, 13.64 \pm 1.80 \mathrm{pmol} / \mathrm{L}$ (0.8-2.0 ng/dL) and <60 kIU/L for TSH, FT4 and TPO-Abs respectively. Ferritin reference values are $15-300 \mu \mathrm{g} / \mathrm{L}$. The total imprecision CVs were 6.9, 4.2, 7.6 and 3.7\% for TSH, FT4, TPO-abs and ferritin respectively. For conversion of FT4, $1 \mathrm{ng} / \mathrm{dL}=12.9 \mathrm{pmol} / \mathrm{L}$.

\section{Statistical analysis}

Data were stored in a Microsoft Excel database and for the pregnancy outcomes in an adapted database 


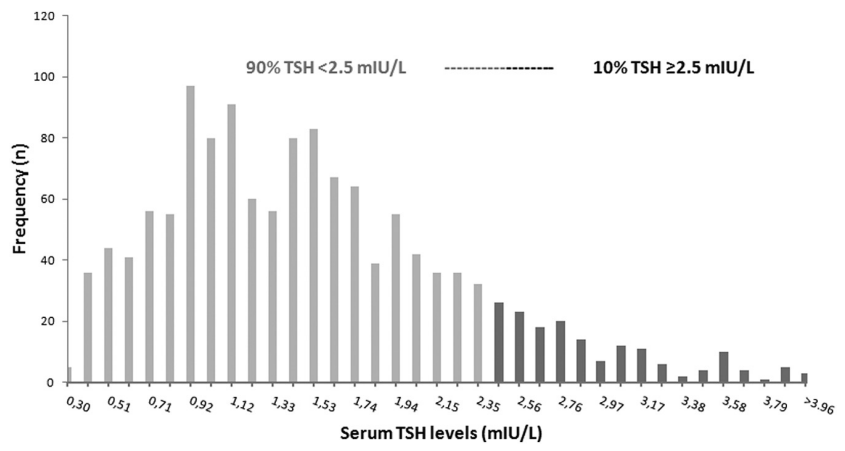

Figure 2

Histogram of frequency distribution of serum TSH levels during the first trimester.

(Cognos). Statistical analyses were performed using Stata 11.2 software (Lakeway Drive, Texas, USA). Continuous data were expressed as median (IQR) when not normally distributed and as mean \pm S.D. for normally distributed data. Categorical data were presented as number (percentage) of cases. Differences between groups (TSH $<$ and $\geq 2.5 \mathrm{mIU} / \mathrm{L}$ ) were analyzed by Fisher's exact tests for categorical data and by the Mann-Whitney $U$ test for continuous data. Correlations between continuous variables were quantified using Spearman's $\rho$ correlation coefficient.

The impact of the independent variables (with TSH and FT4 as continuous data) on the dependent categorical variables (demographic and pregnancy outcome data) were explored by a logistic regression and when an association was present in the univariable analysis, this was then further corrected for confounders in a multivariable model for the pregnancy outcomes (main aim of the study).

All statistical tests were considered significant whenever $P<0.05$.

\section{Results}

Figure 2 shows a histogram of frequency distribution of serum TSH levels during the first trimester.

Ninety percent of women had TSH levels $<2.5 \mathrm{IU} / \mathrm{L}$ and $10 \%$ between 2.5 and $4.0 \mathrm{IU} / \mathrm{L}$. Among women with TSH levels $\geq 2.5 \mathrm{IU} / \mathrm{L}, 90 \%$ had TSH levels $<3.25 \mathrm{IU} / \mathrm{L}$.

Table 1 shows thyroid function, iron status and demographic characteristics in all women and according to the thyroid function status.

Serum TSH and FT4 levels from all women included were $1.47 \pm 0.73 \mathrm{IU} / \mathrm{L}$ and $13.64 \pm 1.80 \mathrm{pmol} / \mathrm{L}$ respectively. By definition, mean serum TSH levels were lower in the $\mathrm{TSH}<2.5$ group as compared with those in the TSH $\geq 2.5$ group $(1.31 \pm 0.55$ vs $2.98 \pm 0.40 ; P<0.001)$.

Mean age was higher in the TSH $<2.5$ group as compared to that in the $\mathrm{TSH} \geq 2.5$ group $(30.0 \pm 5.8$ vs $28.73 \pm 4.9$ years; $P=0.001$ ), but when age was expressed as 'older age'; i.e. $\geq 35$ years, there was no difference between the groups. Iron status, BMI levels, the prevalence of obesity and smokers were comparable between both study groups.

Table 2 shows obstetric and pregnancy outcome data in all women and according to the thyroid function status.

Parity was higher in TSH $<2.5$ group as compared with that in the TSH $\geq 2.5$ group (median (IQR), $1(0-2)$ vs 1 (0-1); $P=0.001)$; but when expressed as 'high parity' $(\geq 3$ births), no difference was present (13.4\% in the TSH $<2.5$ and $9.1 \%$ in the TSH $\geq 2.5$ group; $P=0.165$ ).

All other outcome measures were comparable between both study groups.

Table 3 shows the Spearman's $\rho$ of the correlations between serum TSH, FT4 levels and iron levels, demographic and pregnancy outcome data.

Serum TSH levels were inversely correlated with FT4 $(r=-0.150 ; P<0.001)$ and age $(r=-0.066 ; P=0.017)$.

Table 1 Baseline and demographic characteristics in all patients and according to the thyroid function status.

\begin{tabular}{|c|c|c|c|c|}
\hline \multirow[b]{2}{*}{ Characteristics } & \multicolumn{3}{|c|}{ TSH (mIU/L) } & \multirow[b]{2}{*}{ P level } \\
\hline & $0.3-4.0$ & $<2.5$ & $\geq 2.5$ & \\
\hline Number of patients $(n(\%))$ & $1321(100)$ & $1189(90)$ & $132(10)$ & \\
\hline TSH (mIU/L, mean \pm s.D.) & $1.47 \pm 0.73$ & $1.31 \pm 0.55$ & $2.98 \pm 0.40$ & $<0.001$ \\
\hline FT4 (pmol/L, mean \pm s.D.) & $13.64 \pm 1.80$ & $13.64 \pm 1.80$ & $13.13 \pm 1.67$ & 0.001 \\
\hline Age (years, mean \pm s.D.) & $29.9 \pm 5.8$ & $30.0 \pm 5.8$ & $28.7 \pm 4.9$ & 0.014 \\
\hline Older age* $(n(\%))$ & $306(23)$ & $283(24)$ & $23(17)$ & 0.099 \\
\hline BMI (kg/m², mean \pm s.D. $)$ & $25.8 \pm 4.9$ & $25.8 \pm 4.9$ & $25.7 \pm 4.4$ & 0.816 \\
\hline Obesity** (n (\%)) & $221(17)$ & $202(17)$ & $19(14)$ & 0.700 \\
\hline Ferritin $(\mu \mathrm{g} / \mathrm{L}$, median $(\mathrm{IQR}))$ & $20(12-36)$ & $20(12-37)$ & $17(11-34)$ & 0.193 \\
\hline Iron deficiency $\left.{ }^{\dagger}, n(\%)\right)$ & $463(35)$ & $410(34)$ & $53(40)$ & 0.195 \\
\hline Smoking (yes, $n(\%))$ & $126(9.5)$ & $108(9.1)$ & $18(13.4)$ & 0.091 \\
\hline
\end{tabular}


Table 3 Spearman's $\rho$ coefficients of correlations between serum TSH, FT4 levels and continuous demographic and pregnancy outcome data.

\begin{tabular}{|c|c|c|}
\hline & $\rho$ & $\boldsymbol{P}$ \\
\hline \multicolumn{3}{|l|}{ TSH (mIU/L) levels correlated with } \\
\hline FT4 (pmol/L) & -0.150 & $<0.001$ \\
\hline Age (years) & -0.066 & 0.017 \\
\hline BMI $\left(\mathrm{kg} / \mathrm{m}^{2}\right)$ & -0.011 & 0.703 \\
\hline Ferritin $(\mu \mathrm{g} / \mathrm{L})$ & -0.053 & 0.054 \\
\hline First prenatal visit (weeks) & 0.119 & $<0.001$ \\
\hline History of miscarriages $(n)$ & 0.005 & 0.857 \\
\hline Pregnancy length (weeks) & 0.016 & 0.571 \\
\hline Birth weight $(\mathrm{kg})$ & -0.003 & 0.903 \\
\hline Postpartum haemorrhage $(\mathrm{mL})$ & -0.017 & 0.547 \\
\hline \multicolumn{3}{|l|}{ FT4 (pmol/L) levels correlated with } \\
\hline TSH (mIU/L) & -0.150 & $<0.001$ \\
\hline Age (years) & -0.096 & $<0.001$ \\
\hline BMI $\left(\mathrm{kg} / \mathrm{m}^{2}\right)$ & -0.089 & 0.001 \\
\hline Ferritin $(\mu \mathrm{g} / \mathrm{L})$ & 0.097 & $<0.001$ \\
\hline First prenatal visit (weeks) & -0.169 & $<0.001$ \\
\hline History of miscarriages $(n)$ & -0.010 & 0.714 \\
\hline Pregnancy length (weeks) & -0.001 & 0.966 \\
\hline Birth weight $(\mathrm{kg})$ & -0.040 & 0.181 \\
\hline Postpartum haemorrhage $(\mathrm{mL})$ & -0.070 & 0.012 \\
\hline
\end{tabular}

A positive correlation was present with the timing of the first prenatal visit $(r=0.119 ; P<0.001)$. Serum FT4 levels were inversely correlated with age $(r=-0.096 ; P<0.001)$, BMI $(r=-0.089 ; P=0.001)$, the timing of the first prenatal visit $(r=-0.169 ; P<0.001)$ and postpartum haemorrhage $(r=-0.070 ; P=0.012)$. A positive correlation was present with ferritin levels $(r=0.097 ; P<0.001)$.

Table 4 shows the results of the univariable logistic regression analysis with iron, demographic and pregnancy outcome data as categorical dependent variables and serum TSH, FT4 levels as continuous independent variables.

Tobacco use was associated with higher serum TSH levels (OR: 1.38 (95\% CI: 1.08-1.74); $P=0.009$ ). A first prenatal visit $>12$ weeks of gestation was also associated with higher serum TSH levels (OR: 1.35 (95\% CI: 1.151.56); $P<0.001)$. No other pregnancy outcomes were associated with serum TSH levels. A first prenatal visit $>12$ weeks of gestation (OR: 0.38 (95\% CI: 0.17-0.89); $P=0.025$ ) and post-partum haemorrhage $>500 \mathrm{~mL}$ (OR: 0.35 (95\% CI: 0.13-0.96); $P=0.040)$ were associated with lower serum FT4 levels. After correction in a multivariable model for other variables associated with post-partum haemorrhage $>500 \mathrm{~mL}$ (IUGR, ID, tobacco use, low birth weight, obesity and preterm birth); the significance with FT4 persisted (OR: 0.33 (95\% CI: $0.11-0.98) ; P=0.045$ ). The absence of associations between serum TSH and FT4 levels and pregnancy outcomes in the univariable model did not change in the multivariable model (data not shown). 
Table 4 Univariable logistic regression analysis with iron, demographic and pregnancy outcome data as categorical dependent variables and serum TSH, FT4 levels as continuous independent variables.

\begin{tabular}{|c|c|c|c|c|}
\hline & \multicolumn{2}{|c|}{ TSH } & \multicolumn{2}{|l|}{ FT4 } \\
\hline & OR $(95 \% \mathrm{Cl})$ & $P$ & OR $(95 \% \mathrm{Cl})$ & $P$ \\
\hline \multicolumn{5}{|l|}{ Demographic/obstetric data } \\
\hline Older maternal age ( $\geq 35$ years) & $0.89(0.74-1.06)$ & 0.201 & $0.84(0.32-2.19)$ & 0.733 \\
\hline Obesity (BMI $\geq 30 \mathrm{~kg} / \mathrm{m}^{2}$ ) & $0.98(0.80-1.20)$ & 0.882 & $1.18(0.40-3.41)$ & 0.765 \\
\hline Iron deficiency (ferritin $<15 \mu \mathrm{g} / \mathrm{L}$ ) & $1.13(0.96-1.32)$ & 0.122 & $0.76(0.32-1.77)$ & 0.533 \\
\hline Tobacco use & $1.38(1.08-1.74)$ & 0.009 & $1.32(0.34-5.07)$ & 0.685 \\
\hline High parity rate $(\geq 3)$ & $0.84(0.66-1.05)$ & 0.119 & $0.46(0.13-1.55)$ & 0.210 \\
\hline History of miscarriages $(\geq 2)$ & $0.89(0.52-1.51)$ & 0.679 & $6.93(0.62-76.73)$ & 0.136 \\
\hline First prenatal visit ( $\geq 12$ weeks) & $1.35(1.15-1.56)$ & $<0.001$ & $0.38(0.17-0.89)$ & 0.025 \\
\hline \multicolumn{5}{|l|}{ Pregnancy outcome data } \\
\hline Gestational diabetes & $1.13(0.94-1.36)$ & 0.188 & $0.46(0.16-1.32)$ & 0.147 \\
\hline Pre-eclampsia & $1.01(0.72-1.40)$ & 0.944 & $1.17(0.19-6.88)$ & 0.861 \\
\hline IUGR & $0.68(0.42-1.12)$ & 0.119 & $1.20(0.11-12.85)$ & 0.880 \\
\hline Preterm birth ( $<37$ weeks) & $1.05(0.75-1.46)$ & 0.762 & $0.89(0.14-5.53)$ & 0.900 \\
\hline Low birth weight $(<2.5 \mathrm{~kg})$ & $0.93(0.66-1.31)$ & 0.700 & $1.11(0.18-6.89)$ & 0.910 \\
\hline Postpartum haemorrhage $(\geq 500 \mathrm{~mL})$ & $0.94(0.78-1.12)$ & 0.486 & $0.35(0.13-0.96)$ & 0.040 * \\
\hline
\end{tabular}

Demographic and pregnancy outcomes data = categorical dependent data $(\mathrm{Y})$; TSH and FT4 levels=continuous independent data $(\mathrm{X})$. * $P=0.045$ after correction for IUGR, ID, tobacco use, low birth weight, obesity and preterm birth. IUGR, intra-uterine growth restriction; $O R$, odds ratio.

\section{Discussion}

The presence of TAI is the most important cause of high serum TSH levels and $\mathrm{SCH}$, and therefore, we excluded in this study women with TAI in order to investigate the impact of variation on serum TSH levels within the normal (non-pregnant) range on pregnancy outcomes $(19,20)$. Serum TSH levels were strongly correlated with FT4 levels, conforming the reliability of FT4 during the first trimester of pregnancy, as it has also been shown in the study by Korevaar and coworkers, in which pregnancy outcomes were better correlated with FT4 than with total T4 (21). Due to the exclusion of women with TAI, a left-shifted TSH distribution was observed with 90\% of women having TSH levels $<2.5 \mathrm{mIU} / \mathrm{L}$. Despite the absence of positive TPO-abs, $10 \%$ of women had serum TSH levels in the upper range of normality $(\geq 2.5 \mathrm{mIU} / \mathrm{L})$ and although the precise reasons for that remain speculative, some hypotheses can be made based on our results. In two studies, performed in the same area in Brussels as our study was, it was shown that thyroglobulin antibodies may be present, even in the absence of TPOabs $(22,23)$. In that by Unuane and coworkers, it was shown that women with Tg-abs had higher mean serum TSH levels as compared with women without antibodies or with TPO-abs (22). We did not measure Tg-abs in our study, since for reimbursement reasons in the Belgian social security system, it is not allowed to measure both antibodies at the same day. The importance of Tg-abs in some patients is also noticed now in the recent ATA guidelines, but at the same time, it is mentioned that the systematic measurement is not recommended (5). Besides the presence of Tg-abs, iron deficiency has also been associated with higher serum TSH levels and $\mathrm{SCH}$ (independently from that of TAI) in two studies $(24,25)$. In the present study, there was also a trend for a higher prevalence of iron deficiency in women with higher serum TSH levels, and (low) FT4 and iron (deficiency) were weakly correlated. Obesity is known to be associated with higher serum TSH levels, probably mediated via a leptin pathway (26). In our study, an inverse correlation between BMI and FT4 levels was present. One theory suggests an increased deiodinase activity that leads to a high conversion rate of T4 to T3 (26). Also in another study higher BMI levels $\left(>25 \mathrm{~kg} / \mathrm{m}^{2}\right)$ were associated with higher prevalence of hypothyroidism during pregnancy, a finding we did not confirm (27). Smoking and smoking cessation have been associated with a lower and a higher prevalence of thyroid antibodies respectively (28). Besides the impact on the immune system, smoking has also been associated with a dose-dependent decrease of serum TSH, induced by activation of the sympathetic nervous system (increasing FT3 and FT4 levels). However, in iodine-deficient regions (such as Belgium with a median (IQR) urinary iodine of 117 (70-189) $\mu \mathrm{g} / \mathrm{L}$ in pregnant women), slightly greater thyroid sizes were observed caused by competitive inhibition of thyroidal iodide uptake by thiocyanate $(28,29)$. The prevalence of smokers was comparable between women with a low and high normal TSH levels, but smoking was associated with higher serum TSH levels. We cannot 
provide the precise underlying mechanisms explaining this association because we excluded women with TAI and did not report on smoking cessation. Age was slightly inversely correlated with serum TSH and strongly with FT4 levels. In literature, older age has been associated with more thyroid dysfunction in one study, but in two others, there was no impact of older age on serum TSH levels or the prevalence of $\operatorname{SCH}(19,27,30)$. In our study, age was inversely correlated with serum TSH and especially with FT4 levels, but no associations between age and important pregnancy outcomes were present. Parity was inversely correlated with serum TSH and although causality cannot be proven, women with lower TSH levels might have become more easily pregnant. However, when parity was defined as high parity $(\geq 3)$, no association with TSH/ FT4 was present, in analogy with a large Danish cohort study (27). We did not measure hCG levels in our study, although it is known to be an important confounding factor in the interpretation of serum TSH levels, especially during the first trimester $(19,31)$. As surrogate marker of hCG, we included the timing of the first prenatal visit and in analogy with the peak hCG levels that decrease after the first trimester of pregnancy, a first prenatal visit after the 12th week of gestation was correlated with higher serum TSH and lower FT4 levels.

The prevalence of GDM was comparable between women with high and low normal TSH levels and no correlations with TSH and FT4 levels were present. Also in a recent Chinese study, GDM was only associated with SCH and TAI, but not with TSH/FT4 levels (32). The prevalence of pre-eclampsia in our cohort (5.4\%) was in the range obtained in a large study cohort, with an overall incidence of hypertensive disorders of 6.2, 8.5 and $10.9 \%$ in women with subclinical hyperthyroidism, euthyroid women and $\mathrm{SCH}$, respectively (33). In a study, higher FT4 levels in early pregnancy were associated with higher vascular resistance in the second and third trimesters in both the maternal and foetal placental compartment and that might have explained the association between FT4 and pre-eclampsia (34). In our study, FT4 levels and preeclampsia were not associated what in part might have been due to the exclusion of women with suppressed serum TSH levels. Both $\mathrm{SCH}$ and hyperthyroidism have been associated with IUGR, maybe due to the imbalance in thyroid hormones that are needed for normal foetal development $(35,36)$ and furthermore, might an impact of thyroid hormones on the placental haemodynamics have played a role in the development of IUGR (34). In our study, no association was observed between IUGR and TSH/FT4 levels. Preterm delivery has been associated with the presence of SCH due to TAI, but not with $\mathrm{SCH}$ as such $(1,2)$. However, in a recent study, it was nicely shown that after correction for maternal age, BMI and preeclampsia, the association between thyroid dysfunction and preterm delivery was absent (37). In our study, preterm delivery was little more frequent in women with higher normal TSH levels, but without reaching statistical significance. We did not observe an association between (low) birth weight and TSH/FT4 levels, in agreement with most results in literature (2), although two studies associated it with overt hypothyroidism and high FT4 levels respectively $(35,38)$. Postpartum haemorrhage was inversely correlated with FT4 levels. There is a well-known association between thyroid dysfunction and an altered menstruation pattern and between hypothyroidism and an increased bleeding tendency in general; a mechanism that is probably mediated via an impact of thyroid hormones on the production of coagulation factors in the liver $(20,39)$.

Some weaknesses of our study were the absence of Tg-abs and hCG levels, two variables of which we explained the importance previously in the discussion and the fact that the ethnic backgrounds of the women were not included, a variable that might influence TSH levels (40).

Recent data have shown that LT4 treatment of pregnant women with TSH levels $<4.0 \mathrm{mIU} / \mathrm{L}$ had a higher prevalence of preterm deliveries and pre-eclampsia as compared with women with TSH levels $\geq 4.0 \mathrm{mIU} / \mathrm{L}$ (6). The authors did not provide a clear explanation for their observations, what might have been due to the retrospective setting of the study. However, based on our study results, we believe that the lower serum TSH levels were not the main reason for their observations. Other explanations could have been a detrimental effect of TAI (no data were provided in their study) or an overtreatment with LT4 leading to peak concentrations of T4 and a negative impact on the placental physiology $(4,34)$.

Our data add evidence to the proposal of the revised guidelines on the management of thyroid dysfunction during pregnancy, in which it is recommended against LT4 treatment in pregnant women without TAI and high normal serum TSH levels $(<4.0 \mathrm{mIU} / \mathrm{L}$ or $<$ upper limit of institutional cut-off) (5). Although this study was not designed to investigate the impact of TAI and higher serum TSH levels $(>4.0 \mathrm{mIU} / \mathrm{L})$ on pregnancy outcomes, the fact that their exclusion in the present study was associated with the absence of impaired pregnancy outcomes, highlights indirectly that these two factors are most probably the ones that can hamper successful ongoing pregnancies. Further studies should focus on the 
impact of these factors on pregnancy outcomes, in order to determine the best candidates for LT4 treatment.

\section{Conclusion}

Variation in thyroid function within the normal (nonpregnant) range during the first trimester of pregnancy in women free of thyroid disease was not associated with altered pregnancy outcomes. Ten percent of women without TPO antibodies had TSH levels in the upper limit of normality, what might have been due to other pregnancy related conditions such as obesity or iron deficiency. Our results provide new evidence in favour of the recommendation against LT4 treatment in pregnant women with high normal TSH levels and no TPO antibodies.

\section{Declaration of interest}

Kris Poppe received lecture fees from the Merck company (Thyroid symposium) in 2014, the IBSA Institut Biochimique SA (satellite meeting of the European Thyroid Association) in 2016 and the Berlin-Chemie AG company (ETA educational thyroid meeting) in 2017.

\section{Funding}

This research did not receive any specific grant from any funding agency in the public, commercial or not-for-profit sector.

\section{Acknowledgements}

The authors would like to thank Dr D Willems for provisions implemented by the laboratory.

\section{References}

1 Van den Boogaard E, Vissenberg R, Land J, Van Wely M, Van der Post J, Goddijn M \& Bisschop PH. Significance of (sub)clinical thyroid dysfunction and thyroid autoimmunity before conception and in early pregnancy: a systematic review. Human Reproduction Update 201117 605-619. (https://doi.org/10.1093/humupd/ dmr024)

2 Chan S \& Boelaert K. Optimal management of hypothyroidism, hypothyroxinaemia and euthyroid TPO antibody positivity preconception and in pregnancy. Clinical Endocrinology 201582 313-326. (https://doi.org/10.1111/cen.12605)

3 Maraka S, Ospina NM, O'Keeffe DT, Espinosa De Ycaza AE, Gionfriddo MR, Erwin PJ, Coddington CC 3rd, Stan MN, Murad MH \& Montori VM. Subclinical hypothyroidism in pregnancy: a systematic review and meta-analysis. Thyroid 201626 580-590. (https://doi.org/10.1089/thy.2015.0418)

4 De Groot L, Abalovich M, Alexander EK, Amino N, Barbour L, Cobin RH, Eastman CJ, Lazarus JH, Luton D, Mandel SJ et al. Management of thyroid dysfunction during pregnancy and postpartum: an Endocrine Society clinical practice guideline. Journal of Clinical Endocrinology and Metabolism 201297 2543-2565. (https://doi.org/10.1210/jc.2011-2803)
5 Alexander EK, Pearce EN, Brent GA, Brown RS, Chen H, Dosiou C, Grobman WA, Laurberg P, Lazarus JH, Mandel SJ et al. Guidelines of the American Thyroid Association for the diagnosis and management of thyroid disease during pregnancy and the postpartum. Thyroid 201727 315-389. (https://doi.org/10.1089/thy.2016.0457)

6 Maraka S, Mwangi R, McCoy RG, Yao X, Sangaralingham LR, Singh Ospina NM, O'Keeffe DT, De Ycaza AE, Rodriguez-Gutierrez R, Coddington CC 3rd et al. Thyroid hormone treatment among pregnant women with subclinical hypothyroidism: US national assessment. BMJ 201725 356. (https://doi.org/10.1136/bmj.i6865)

7 Nazarpour S, Ramezani Tehrani F, Simbar M, Tohidi M, Alavi Majd H $\&$ Azizi F. Effects of levothyroxine treatment on pregnancy outcomes in pregnant women with autoimmune thyroid disease. European Journal of Endocrinology 2017176 253-265. (https://doi.org/10.1530/ EJE-16-0548)

8 Negro R, Schwartz A \& Stagnaro-Green A. Impact of levothyroxine in miscarriage and preterm delivery rates in first trimester thyroid antibody-positive women with TSH less than $2.5 \mathrm{mIU} / \mathrm{L}$. Journal of Clinical Endocrinology and Metabolism 2016101 3685-3690. (https://doi.org/10.1210/jc.2016-1803)

9 Maraka S, Singh Ospina NM, O'Keeffe DT, Rodriguez-Gutierrez R, Espinosa De Ycaza AE, Wi CI, Juhn YJ, Coddington CC 3rd \& Montori VM. Effects of increasing levothyroxine on pregnancy outcomes in women with uncontrolled hypothyroidism. Clinical Endocrinology 201786 150-155. (https://doi.org/10.1111/cen.13168)

10 Benhadi N, Wiersinga W, Reitsma J, Vrijkotte G \& Bonsel G. Higher maternal TSH levels in pregnancy are associated with increased risk for miscarriage, fetal or neonatal death. European Journal of Endocrinology 2009160 985-991. (https://doi.org/10.1530/EJE-080953)

11 Negro R, Schwartz A, Gismondi R, Tinelli A, Mangieri T \& StagnaroGreen A. Increased pregnancy loss rate in thyroid antibody negative women with TSH levels between 2.5 and 5.0 in the first trimester of pregnancy. Journal of Clinical Endocrinology and Metabolism 201095 E44-E48. (https://doi.org/10.1210/jc.2010-0340)

12 Roef G, Lapauw B, Goemaere S, Zmierczak HG, Toye K, Kaufman JM $\&$ Taes Y. Body composition and metabolic parameters are associated with variation in thyroid hormone levels among euthyroid young men. European Journal of Endocrinology 2012167 719-726. (https://doi.org/10.1530/EJE-12-0447)

13 Chen S, Zhou X, Zhu H, Yang H, Gong F, Wang L, Zhang M, Jiang Y, Yan C, Li J et al. Preconception TSH and pregnancy outcomes: a population-based cohort study in 184611 women. Clinical Endocrinology 201786 816-824. (https://doi.org/10.1530/EJE-120447)

14 Liu H, Shan Z, Li C, Mao J, Xie X, Wang W, Fan C, Wang H, Zhang H, Han C et al. Maternal subclinical hypothyroidism, thyroid autoimmunity, and the risk of miscarriage: a prospective cohort study. Thyroid 201424 1642-1649. (https://doi.org/10.1089/ thy.2014.0029)

15 Robinson GE. Pregnancy loss. Best Practice and Research Clinical Obstetrics and Gynaecology 201428 169-178. (https://doi. org/10.1016/j.bpobgyn.2013.08.012)

16 Romo A, Carceller R \& Tobajas J. Intrauterine growth retardation (IUGR): epidemiology and etiology. Pediatric Endocrinology Reviews 20096 (Supplement 3) 332-336. (https://doi.org/10.1016/j. bpobgyn.2013.08.012)

17 Mack LR \& Tomich PG. Gestational diabetes: diagnosis, classification, and clinical care. Obstetrics and Gynecology Clinics of North America 201744 207-217. (https://doi.org/10.1016/j.ogc.2017.02.002)

18 Payne B, Magee LA \& von Dadelszen P. Assessment, surveillance and prognosis in pre-eclampsia. Best Practice and Research Clinical Obstetrics and Gynaecology 201125 449-462. (https://doi. org/10.1016/j.bpobgyn.2011.02.003)

19 Korevaar TI, Nieboer D, Bisschop PH, Goddijn M, Medici M, Chaker L, de Rijke YB, Jaddoe VW, Visser TJ, Steyerberg EW et al. 
Risk factors and a clinical prediction model for low maternal thyroid function during early pregnancy: two population-based prospective cohort studies. Clinical Endocrinology 201685 902-909. (https://doi. org/10.1111/cen.13153)

20 Krassas GE, Poppe K \& Glinoer D. Thyroid function and human reproductive health. Endocrine Reviews 201031 702-755. (https://doi. org/10.1210/er.2009-0041)

21 Korevaar TI, Chaker L, Medici M, de Rijke YB, Jaddoe VW, Steegers EA, Tiemeier H, Visser TJ \& Peeters RP. Maternal total T4 during the first half of pregnancy: physiologic aspects and the risk of adverse outcomes in comparison with free T4. Clinical Endocrinology 201685 757-763. (https://doi.org/10.1111/cen.13106)

22 Unuane D, Velkeniers B, Anckaert E, Schiettecatte J, Tournaye H, Haentjens P \& Poppe K. Thyroglobulin autoantibodies: is there any added value in the detection of thyroid autoimmunity in women consulting for fertility treatment? Thyroid 201323 1022-1028. (https://doi.org/10.1089/thy.2012.0562)

23 Moreno-Reyes R, Glinoer D, Van Oyen H \& Vandevijvere S. High prevalence of thyroid disorders in pregnant women in a mildly iodine-deficient country: a population-based study. Journal of Clinical Endocrinology and Metabolism 201398 3694-3701. (https://doi. org/10.1210/ jc.2013-2149)

24 Veltri F, Decaillet S, Kleynen P, Grabczan L, Belhomme J, Rozenberg S, Pepersack T \& Poppe K. Prevalence of thyroid autoimmunity and dysfunction in women with iron deficiency during early pregnancy: is it altered? European Journal of Endocrinology 2016175 191-199. (https://doi.org/10.1530/EJE-16-0288)

25 Zimmermann MB, Burgi H \& Hurrell RF. Iron deficiency predicts poor maternal thyroid status during pregnancy. Journal of Clinical Endocrinology and Metabolism 200792 3436-3440. (https://doi. org/10.1210/jc.2007-1082)

26 Rotondi M, Magri F \& Chiovato L. Thyroid and obesity: not a oneway interaction. Journal of Clinical Endocrinology and Metabolism 2011 96 344-346. (https://doi.org/10.1210/jc.2007-1082)

27 Andersen SL, Olsen J \& Laurberg P. Maternal thyroid disease in the Danish National Birth Cohort: prevalence and risk factors. European Journal of Endocrinology 2016174 203-212. (https://doi.org/10.1530/ EJE-15-0816)

28 Wiersinga WM. Smoking and thyroid. Clinical Endocrinology 201379 145-151. (https://doi.org/10.1111/cen.12222)

29 Vandevijvere S, Mourri A, Amsalkhir S, Avni F, Van Oyen H \& Moreno-Reyes R. Fortification of bread with iodised salt corrected iodine deficiency in school-aged children but not in their mothers: a national cross-sectional survey in Belgium. Thyroid 201222 1046-1053. (https://doi.org/10.1089/thy.2012.0016)

30 Diéguez M, Herrero A, Avello N, Suárez P, Delgado E \& Menéndez E. Prevalence of thyroid dysfunction in women in early pregnancy: does it increase with maternal age? Clinical Endocrinology 201684 121-126. (https://doi.org/10.1111/cen.12693)

31 Grün JP, Meuris S, De Nayer P \& Glinoer D. The thyrotrophic role of human chorionic gonadotrophin (hCG) in the early stages of twin (versus single) pregnancies. Clinical Endocrinology 199746 719-725 (https://doi.org/10.1046/j.1365-2265.1997.2011011.x)

32 Ying H, Tang YP, Bao YR, Su XJ, Cai X, Li YH \& Wang DF. Maternal TSH level and TPOAb status in early pregnancy and their relationship to the risk of gestational diabetes mellitus. Endocrine $2016 \mathbf{5 4}$ 742-750. (https://doi.org/10.1007/s12020-016-1022-6)

33 Wilson KL, Casey BM, McIntire DD, Halvorson LM \& Cunningham FG. Subclinical thyroid disease and the incidence of hypertension in pregnancy. Obstetrics and Gynecology 2012119 315-320. (https://doi.org/10.1097/AOG.0b013e318240de6a)

34 Barjaktarovic M, Korevaar TI, Chaker L, Jaddoe VW, de Rijke YB, Visser TJ, Steegers EA \& Peeters RP. The association of maternal thyroid function with placental hemodynamics. Human Reproduction 201732 653-661. (https://doi.org/10.1093/humrep/dew357)

35 Su PY, Huang K, Hao JH, Xu YQ, Yan SQ, Li T, Xu YH \& Tao FB. Maternal thyroid function in the first twenty weeks of pregnancy and subsequent fetal and infant development: a prospective population-based cohort study in China. Journal of Clinical Endocrinology and Metabolism 201196 3234-3241. (https://doi. org/10.1210/jc.2011-0274)

36 Rivkees SA, Bode HH \& Crawford JD. Long-term growth in juvenile acquired hypothyroidism: the failure to achieve normal adult stature. New England Journal of Medicine 1988318 599-602. (https://doi. org/10.1056/NEJM198803103181003)

37 Saki F, Dabbaghmanesh MH, Ghaemi SZ, Forouhari S, Ranjbar Omrani G \& Bakhshayeshkaram M. Thyroid function in pregnancy and its influences on maternal and fetal outcomes. International Journal of Endocrinology and Metabolism 201412 e19378. (https://doi. org/10.5812/ijem.19378)

38 Vrijkotte TG, Hrudey EJ \& Twickler MB. Early maternal thyroid function during gestation is associated with fetal growth, particularly in male newborns. Journal of Clinical Endocrinology and Metabolism 2017102 1059-1066. (https://doi.org/10.1210/jc.2016-3452)

39 Kyriakakis N, Lynch J, Ajjan R \& Murray RD. The effects of pituitary and thyroid disorders on haemostasis: potential clinical implications. Clinical Endocrinology 201684 473-484. (https://doi.org/10.1111/ cen.12767)

40 Veltri F, Belhomme J, Kleynen P, Grabczan L, Rozenberg S, Pepersack T \& Poppe K. Maternal thyroid parameters in pregnant women with different ethnic backgrounds: do ethnicityspecific reference ranges improve the diagnosis of subclinical hypothyroidism? Clinical Endocrinology 201786 830-836. (https://doi.org/10.1111/cen.13340)

Received 1 August 2017

Revised version received 27 October 2017

Accepted 28 November 2017 